\title{
SISTEM INFORMASI PROMOSI DAN PEMESANAN PAKAIAN BERBASIS WEB PADA JASKO ANNAZMA MOSLEM WEAR CIGOMBONG - INDONESIA
}

\author{
Adi Haryanto \\ Fakultas Teknik dan Sains, Prodi Teknik Informatika \\ adi_haryanto@yahoo.com
}

\begin{abstract}
Abstrak
Jasko An Nazma Moslem Wear merupakan perusahaan konveksi yang bergerak di bidang produk dan jasa pembuatan pakaian muslimyang berlokasi di Jalan Bata Alam Kec.Cigombong Kab.Bogor. Pengalaman menekuni bidang usaha sejak 2015 hingga sekarang. Perusahaan ini berkonsentrasi pada penjualan pakaian muslim seperti Jasko, peci, gamis dan almamater namun kegiatan jual beli masih dilakukan secara manual, pemasaran dan promosi produk hanya mencakup area yang terbatas dan hanya mengandalkan sistem pemasaran dengan pemesanan melalui telepon dan pengenalan produk masih dilakukan secara offline. untuk melihat informasi mengenai produk yang dibutuhkan, pelanggan harus datang ke lokasi usaha untuk mengetahui informasi secara detail. Untuk menigkatkan pelayanan jasa yang mereka tawarkan kepada pelanggan Jasko An Nazma Moslem Wear memerlukan sistem informasi secara online berbasis web agar produknya lebih dikenal serta membuat sistem database penjualannya. Perancangan sistem pada Jasko An Nazma Moslem Wear dibangun berdasarkan (1) analisa sistem (2) perancangan sistem, (3) implementasi sistem. Analisa sistem pengumpulan data dengan carapengamatan kegiatan transaksi jual beli, wawancara terhadap pemilik usaha dalam hal penjualan dan dokumentasi untuk pengarsipan data yang didapat dari pemilik usaha yang diperlukan dalam pengembangan sistem. Perancangan sistem dibuat melalui tahapan diagram konteks (DFD level 0), DFD level 1), entity relationship diagram (ERD), desain input dan output serta struktur menu program. Implementasi sistem menggunakan program Microsoft visio, sublime text, adobe photoshop dan XAMPP server. Diharapkan sistem ini dapat membantu Jasko An Nazma Moslem Wear dalam meningkatkan kinerja perusahaan baik bertambahnya pelanggan, omset naik dan mempermudah sistem administrasinya.
\end{abstract}

Kata kunci : Sistem Informasi,pemasaran,website,jasko Annazma Moslem Wear,CigombongIndonesia

\begin{abstract}
Jasko An Nazma Moslem Wear is a convection company engaged in the manufacture of Muslim clothing products and services located at Jalan Bata Alam Kec. Cigombong, Bogor Regency. Experience in the field of business since 2015 until now. The company concentrates on selling Muslim clothing such as Jasko, peci, robe and alma mater, but buying and selling activities are still done manually, product marketing and promotion only covers a limited area and only relies on a marketing system with telephone ordering and product introduction still done offline. to see information about products needed, customers must come to the business location to find out information in detail.

To improve the services they offer to customers Jasko An Nazma Moslem Wear requires an online webbased information system so that its products are better known and create a database sales system. The design of the system in Nazma Moslem Wear Jasko was built based on (1) system analysis (2) system design, (3) system implementation. Analysis of system data collection with observations of buying and selling transactions, interviews with business owners in terms of sales and documentation for archiving data obtained from business owners needed in system development. System design is made through the context diagram stage (DFD level O), DFD level 1), entity relationship diagram
\end{abstract}


$(E R D)$, input and output design and program menu structure. The system implementation uses the Microsoft Visio program, sublime text, Adobe Photoshop and XAMPP server. It is expected that this system can help An Nazma Moslem Wear Co-operative in improving the performance of the company both increasing customers, increasing turnover and simplifying the administrative system.

Keywords: Information System, marketing, website, jasko Annazma Moslem Wear, CigombongIndonesia

\section{PENDAHULUAN}

Perkembangan teknologi informasi dan persaingan bisnis yang semakin pesat, mendorong setiap instansi atau perusahaan untuk tetap mengikuti perkembangannya agar bisa memenangkan persaingan bisnis. Membangun sistem informasi secara online berbasis web adalah strategi yang sangat baik untuk diterapkan karena keberadaan suatu website dapat membantu menyampaikan informasi dan memperluas jangkauan pemasaran serta mampu memberikan kemudahan pada konsumen atau pelanggan untuk melakukan pemesanan secara online. Penerapan E-Commerce mampu menigkatkan pelayanan jasa yang mereka tawarkan kepada pelanggan sebagai alat untuk berkomunikasi dengan konsumen atau pelanggan secara online. E-Commerce (Electronic Commerce) adalah suatu alat yang mempermudah produsen dalam hal berkomunikasi dengan konsumen serta dapat mempermudah produsen dalam pengelolaan produk yang dijual. E-Commerce menekankan pada penggunaan teknologi informasi dan komunikasi dalam transaksi antarbisnis dan antar organisasi dan transaksi antar bisnis dengan konsumen.[1]

Jasko An Nazma Moslem Wear merupakan perusahaan konveksi yang bergerak di bidang produk dan jasa pembuatan pakaian muslimyang berlokasi di Jalan Bata Alam Kec.Cigombong Kab.Bogor. Pengalaman menekuni bidang usaha sejak 2015 hingga sekarang. Perusahaan ini berkonsentrasi pada penjualan pakaian muslim seperti Jasko, peci, gamis dan almamater namun kegiatan jual beli masih dilakukan secara manual, pemasaran dan promosi produk hanya mencakup area yang terbatas dan hanya mengandalkan sistem pemasaran dengan pemesanan melalui telepon dan pengenalan produk masih dilakukan secara offline. untuk melihat informasi mengenai produk yang dibutuhkan, pelanggan harus datang ke lokasi usaha untuk mengetahui informasi secara detail.

\section{METODE PENELITIAN}

\subsection{Tahapan Review}

Penelitian dilaksanakan di Jasko An Nazma Moslem Wear. Dalam tahapan ini peneliti melakukan metode pengumpulan data, metode analisis dan metode pengembangan sistem Dalam metode penelitian dapat dilihat flowchart metode penelitian yang ditunjukkan pada Gambar 1.

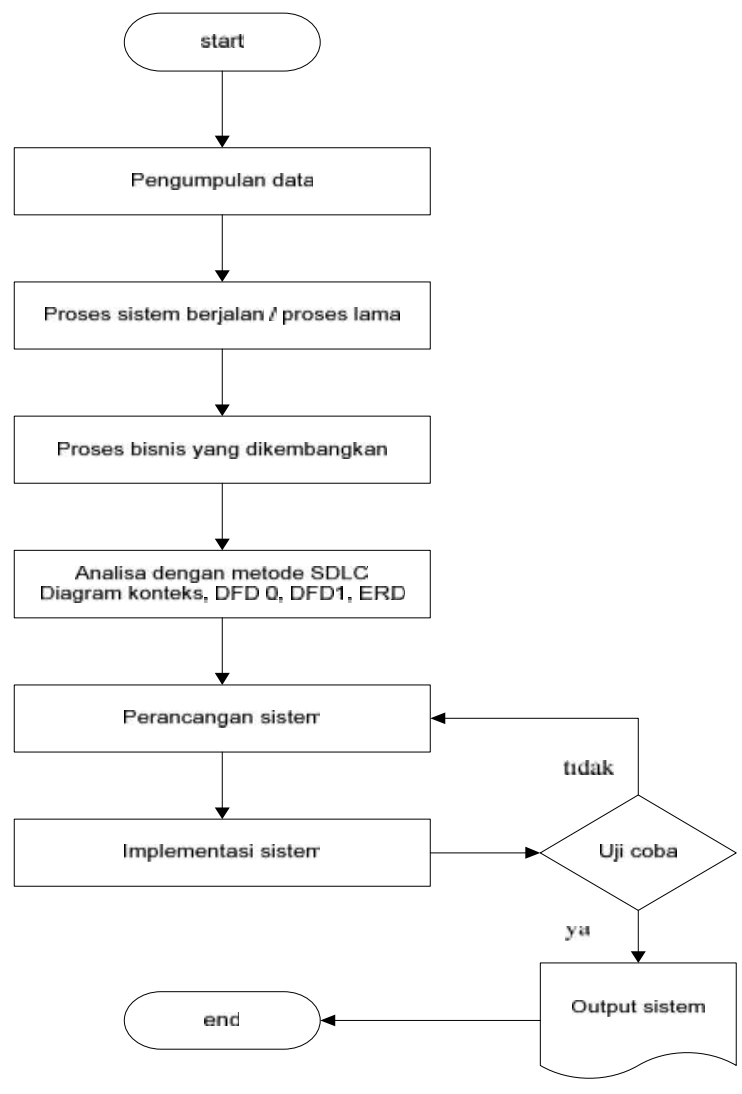
Gambar 1 Proses bisnis penjualan barang yang berjalan

2.2 Metode Pengembangan sistem 
Mengacu pada metode System Development Life Cycle (SDLC) atau Metode Tradisional yang telah dibahas pada landasan teori bahwa SDLC adalah kerangka kerja (framework) yang terstruktur yang berisi proses-proses sekuensial dimana sistem informasi dikembangkan.[3]

Tahapan-Tahapan dalam SDLC (Sistem Development Life Cycle) antara lain:

1. Perencanaan sistem

Lebih menekankan pada aspek studi kelayakan pengembangan sistem. Aktivitasaktivitas yang ada meliputi :

a. Mendefinisikan tujuan dan ruang lingkup pengembangan.pada jasko Annazma Moslem Wear

b. Mengidentifikasi apakah masalahmasalah pada Jasko Annazma Moslem Wear bisa diselesaikan melalui pengembangan sistem.

c. Penentuan prioritas teknologi pada Jasko Annazma Moslem Wear dengan aplikasi visual studio 2013, adobe photoshop,sublime text,dan XAMPP server

2. Analisis sistem

Analisa sistem adalah tahap dimana dilakukan beberapa aktivitas berikut:

\section{a. Analisis Sistem Berjalan}

Analisis berjalan dimaksudkan untuk memahami alur kerja dari sistem yang ada dan saat ini berjalan agar dapat diketahui kekurangan sistem yang ada dan digantikan dengan sistem baru yang diusulkan. Tahap analisis sistem berjalan dilakukan dengan menggambarkan tahap demi tahap proses ke dalam bentuk flowmap. Gambar Flowmap sistem yang saat ini berjalan ditunjukkan pada Gambar 2.

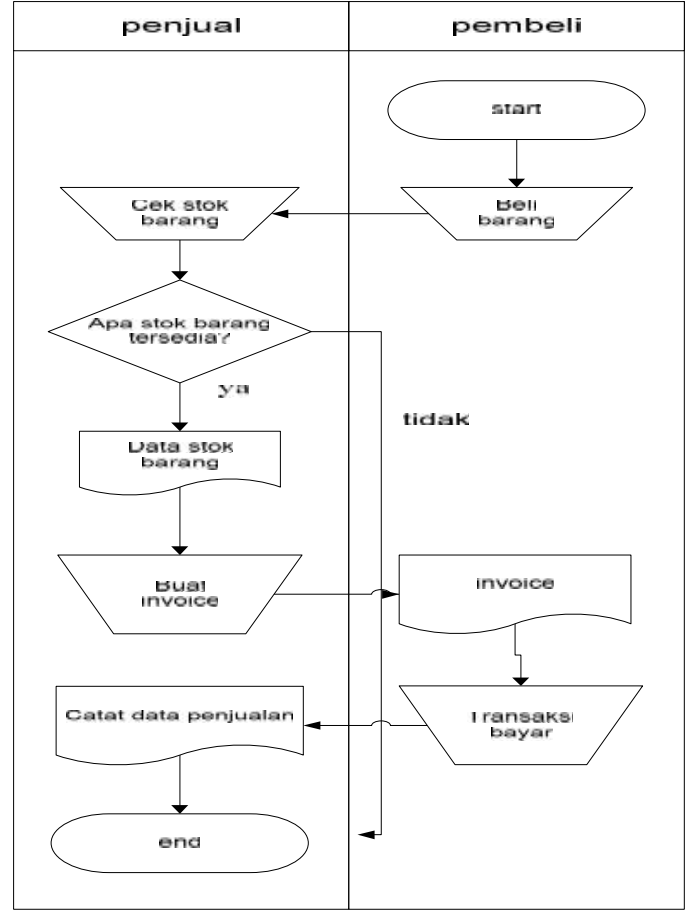

Gambar 2 Proses bisnis penjualan barang yang berjalan

b. Proses bisnis yang dikembangkan

Sistem yang dikembangkan diharapkan dapat mengatasi permasalahan yang terjadi pada pengelolaan sistem di Jasko An Nazma Moslem Wear dan memudahkan proses penjualan sehingga dapat meningkatkan penjualannya. Hasil rancangan proses bisnis yang dikembangkan ditunjukan pada Gambar 3.

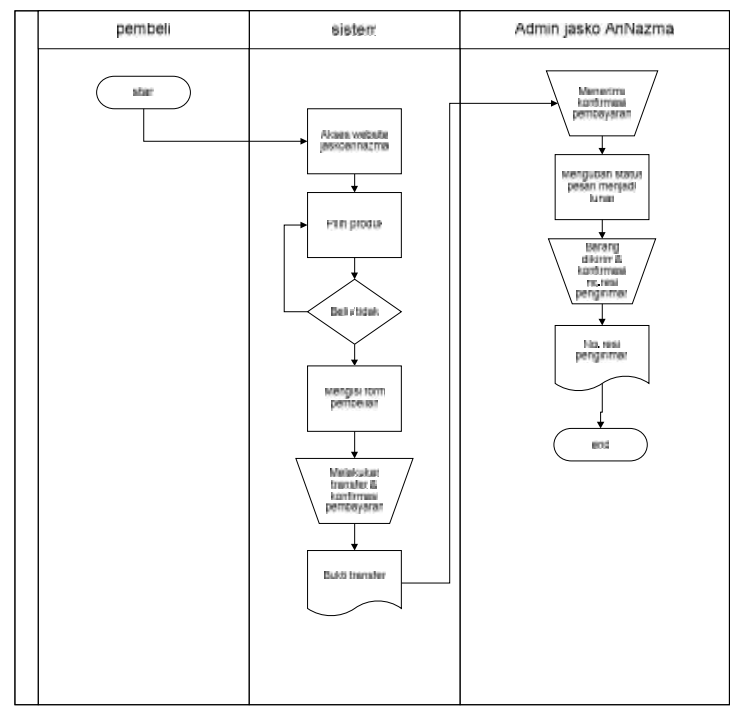

Gambar 3 Proses bisnis penjualan barang yang dikembangkan 
c. Analisis kebutuhan fungsional

Pada hasil analisis mengenai sistem yang berjalan di Jasko An Nazma Moslem Wear, maka didapatkan kebutuhan fungsional yang perlu dibangun antara lain:

1. Menyediakan fasilitas website sebagai media untuk menyajikan informasi kepada konsumen atau pelanggan.

2. Menyediakan fasilitas untuk menambahkan data produk dan data pelanggan

3. Menyediakan fasilitas untuk menambah, mengedit dan menghapus data di dalam sistem yang dapat di akses oleh admin untuk mengontrol keseluruhan sistem

3. Perancangan desain sistem

Pada tahap ini features dan operasi-operasi pada sistem di deskripsikan secara detail. Aktivitas-aktivitas yang dilakukan adalah:

a. Menganalisa interaksi obyek pada Jasko Annazma Moslem Wear dengan perancangan fungsi pada sisem.

b. menganalisa data serta membuat skema database pada Jasko Annazma Moslem Wear.

c. Merancang user interface pada Jasko Annazma Moslem Wear.

\subsection{Perancangan sistem}

Dalam desain kebutuhan fungsional akan dibahas mengenai gambaran diagram konteks, Data Flow Diagram dan Entity Relationship Diagram pada perancangan Sistem Informasi Promosi dan penjualan pada Jasko An Nazma Moslem Wear

\subsubsection{Diagram Konteks (DFD level 0)}

Diagram Konteks adalah diagram yang terdiri dari suatu proses dan menggambarkan ruang linkup suatu sistem di Jasko An Nazma moslem wear. Pembeli yang sudah meiliki hak akses menggunakan sistem penjualan untuk melakukan pemesanan, mendapat informasi kapan barang akan dikirim dan nota untuk bukti pemesanan, sedangkan penjual yang sudah mengisi username \& password memiliki hak akses mengelola data barang,menkonfirmasi pemesanan barang, melihat transaksi penjualan, melihat laporan stok barang. Masing-masing proses ditampilkan pada Gambar 4.

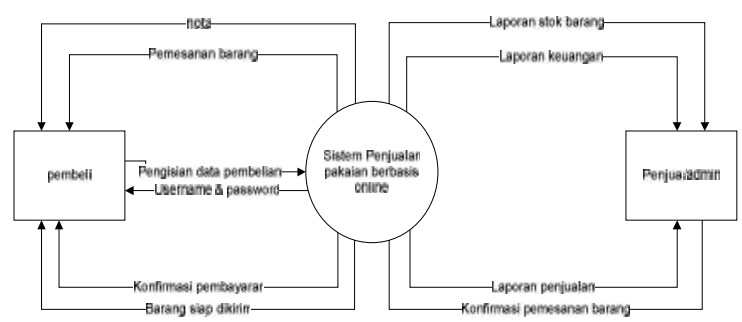

Gambar 4 Diagram konteks (DFD level 0)

\subsubsection{Diagram DFD Level 1}

Sistem dapat dipecah menjadi beberapa proses yaitu proses login, proses input data, proses transaksi dan proses laporan. Dalam DFD Level 1 ini, kedua entitas memiliki proses yang berbeda. Penjual/ Admin memiliki akses ke seluruh sistem, sedangkan pembeli hanya dapat melihat data master yang dikelola oleh penjual/admin yang meliputi menu data master yang meliputi data pelanggan, melakukan transaksi pemesanan masing-masing proses dapat dipecah menjadi beberapa sub-process yang ditampilkan pada Gambar 5.

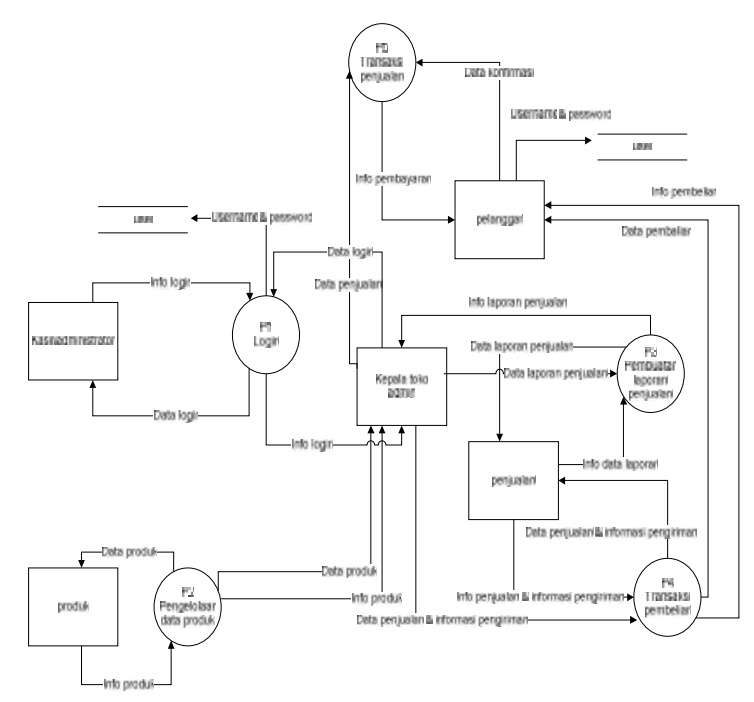

Gambar 5 DFD level 1

\subsubsection{ERD}


ERD (Entity Relationship Diagram) adalah suatu model untuk menjelaskan hubungan antar data dalam basis data berdasarkan objek-objek dasar data yang mempunyai hubungan antar relasi. ERD untuk memodelkan struktur data dan hubungan antar data, untuk menggambarkannya digunakan beberapa notasi dan symbol yang ditampilkan pada Gambar 6 .

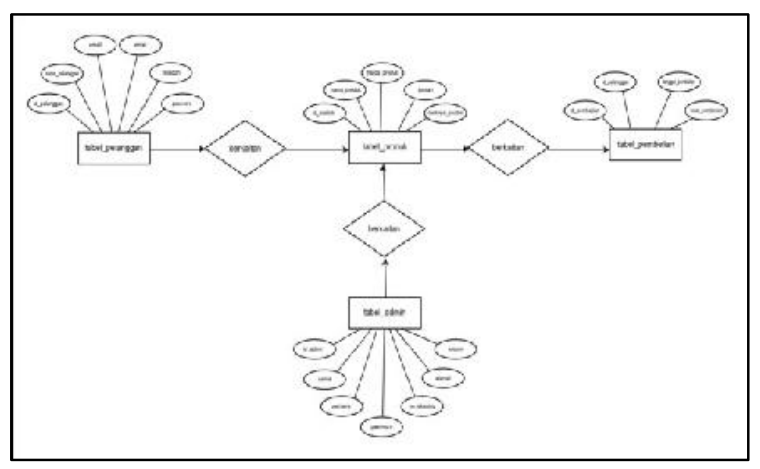

Gambar 6 ERD (Entity Relation Diagram)

\section{HASIL DAN PEMBAHASAN}

\section{Hasil Antarmuka Halaman Website}

1.) Halaman Login

Halaman login merupakan proses masuk ke jaringan komputer dengan memasuki identitas akun yang terdiri dari username dan password untuk mendapatkan hak akses masuk ke halaman administrator seperti yang ditampilkan pada Gambar 7.
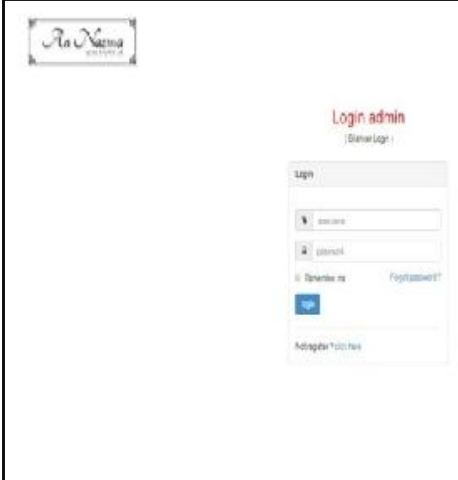

Gambar 7 Hasil antarmuka halaman login

2.) Halaman home administrator Halaman home administrator merupakan halaman untuk admin yang dapat dipergunakan untuk menambah, mengedit maupun menghapus produk. proses masuk ke halaman ini dengan memasuki identitas akun yang terdiri dari username dan password yang sudah terdaftar didalam database admin yang ditampilkan pada Gambar 8 .

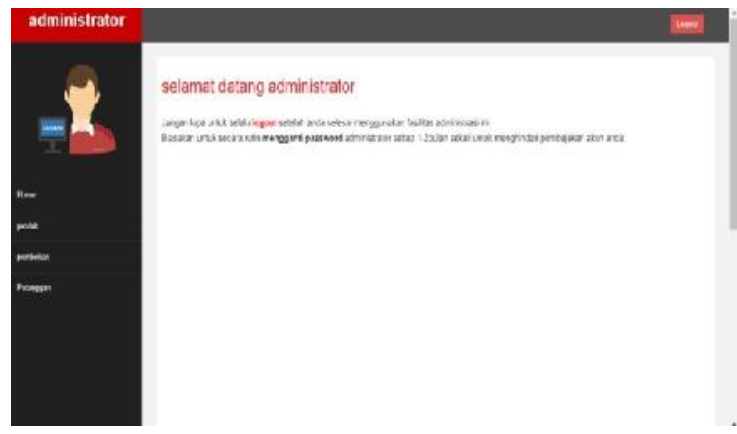

Gambar 8 Hasil antarmuka halaman home administrator

3.) Halaman produk

Halaman produk merupakan halaman administrator yang berfungsi untuk menambah, mengedit maupun menghapus produk. Halaman ini berisi tabel data produk meliputi nama produk, harga produk, foto produk, dan aksi yang berisi tombol ubah dan hapus yang ditampilkan pada Gambar 9.

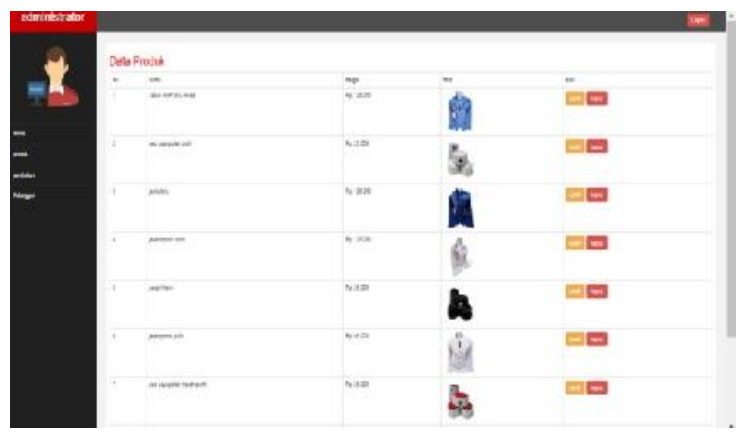

Gambar 9 Hasil antarmuka halaman produk

4.) Halaman pelanggan

Halaman pelanggan merupakan halaman yang berisi tabel dari data pelanggan yang meliputi nama, alamat, email telepon, dan aksi meliputi tombol hapus yang berfungsi 
untuk menghapus data pelanggan yang ditampilkan pada Gambar 10.

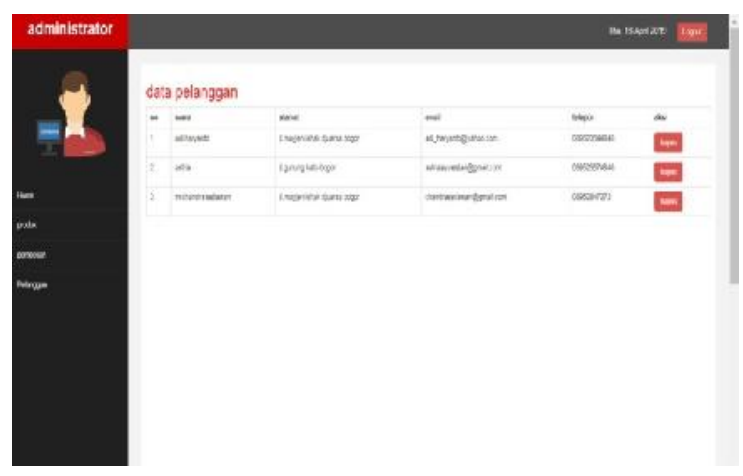

\section{Gambar 10 Hasil antarmuka data pelanggan}

5.) Halaman pembelian

Halaman pembelian merupakan halaman yang berisi tabel dari data pembeli yang meliputi nama pelanggan, tanggal pembelian, total pembelian dan tombol detail yang ditampilkan pada Gambar 11.

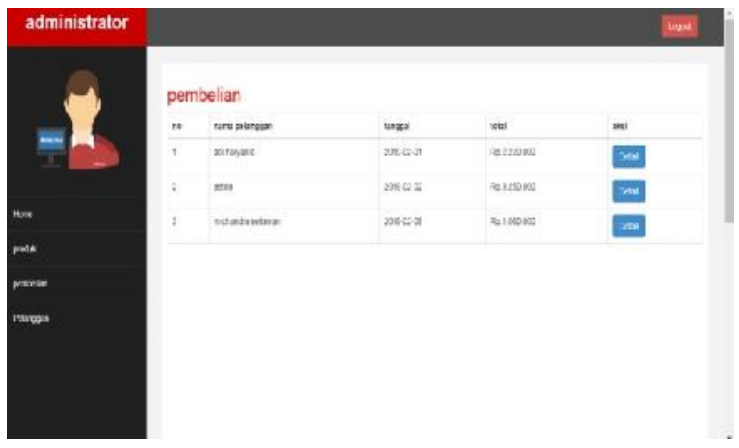

Gambar 11 Hasil antarmuka data pembelian

6.) Halaman detail pembelian Halaman detail pembelian merupakan halaman yang berisi nama pembeli,telepon,email,tanggal pembelian dan total pembelian serta tabel yang meliputi nama produk yang dibeli, harga, jumlah dan subtotal yang ditampilkan pada Gambar 12.

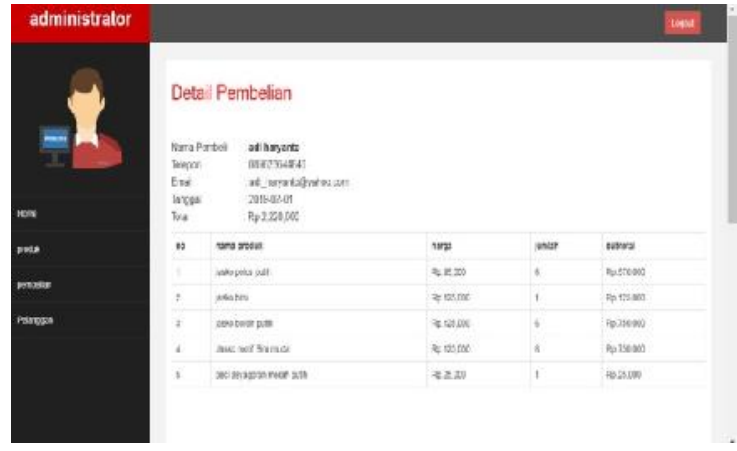

\section{Gambar 12 Hasil antarmuka detail pembelian}

7.) Halaman utama produk

Halaman utama produk merupakan halaman yang berisi logo di sebelah atas kiri dan menu di bagian atas kanan atau header.konten berisi foto produk, nama produk,harga produk dan tombol beli yang ditampilkan pada Gambar 13.

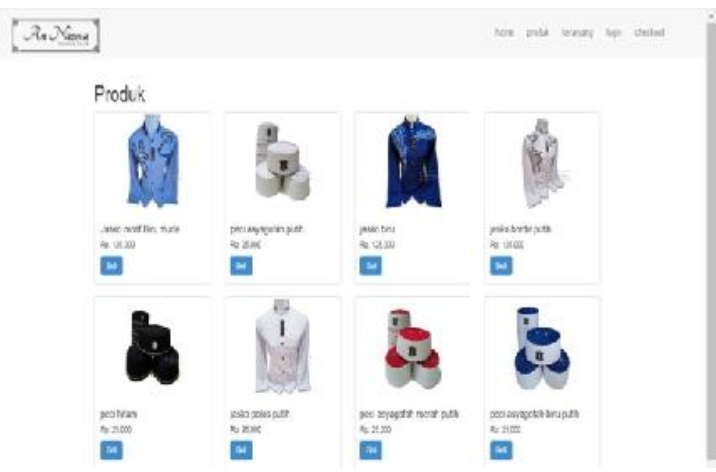

Gambar 13 Desain antarmuka halaman utama produk

8.) Halaman utama login

Halaman utama home merupakan halaman yang berisi logo di sebelah atas kiri dan menu di bagian atas kanan atau header. Konten berisi tabel login meliputi username, password dan tombol login seperti yang ditampilkan pada Gambar 14. 


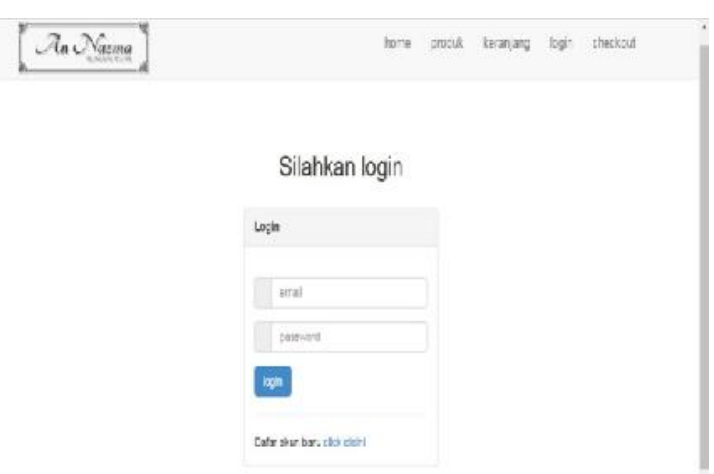

Gambar 14 Desain antarmuka halaman utama login

9.) Halaman utama home

Halaman utama home merupakan halaman yang berisi logo di sebelah atas kiri dan menu di bagian atas kanan atau header. Foto di bawah header dan konten yang berisi profil toko, langkah pemesanan dan kontak seperti yang ditamtampilkan pada Gambar 4.14.

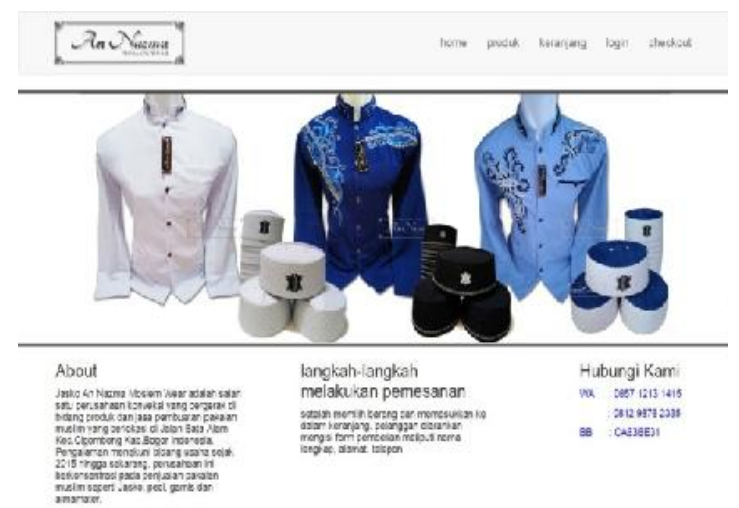

\section{Gambar 15 Desain antarmuka halaman utama home}

10.) Halaman utama keranjang

Halaman utama keranjang merupakan halaman yang berisi logo di sebelah atas kiri dan menu di bagian atas kanan atau header. Konten berisi tabel yang meliputi nama produk, harga, jumlah beli, subtotal dan aksi yang meliputi tombol hapus untuk menghapus data produk didalam keranjang serta tombol lanjut belanja dengan fungsi kembali ke halaman produk dan tombol checkout seperti yang ditampilkan pada Gambar 16.

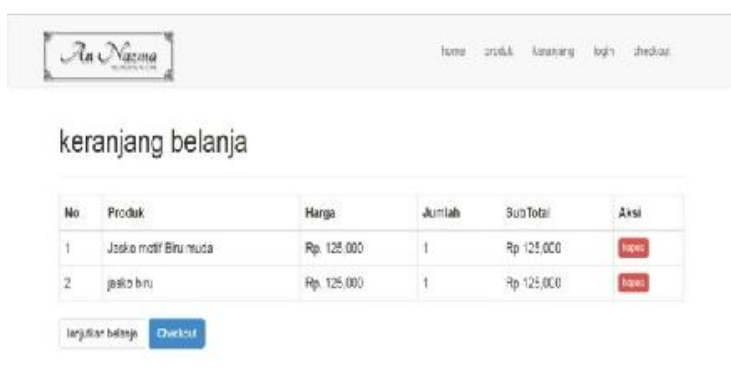

\section{Gambar 16 Hasil antarmuka halaman utama keranjang}

11.) Halaman utama checkout Halaman utama checkout merupakan halaman yang berisi logo di sebelah atas kiri dan menu di bagian atas kanan atau header. Konten berisi tabel yang meliputi nama produk, harga, jumlah beli, subtotal dan total belanja. Serta berisi nama pelanggan, telepon, dan opsi ongkos kirim serta tombol checkout seperti yang ditampilkan pada Gambar 17.

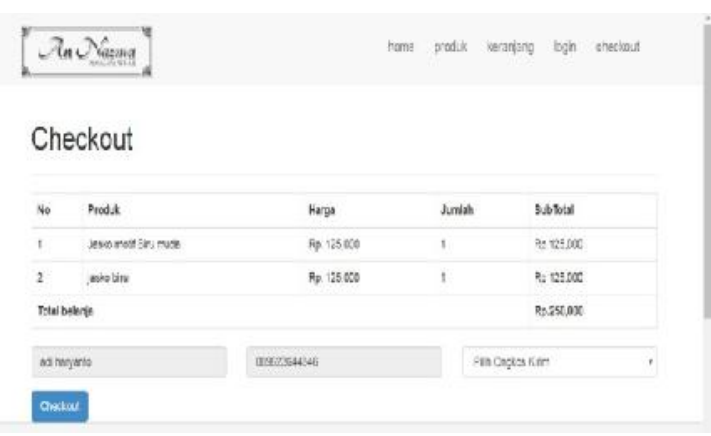

Gambar 17 Hasil antarmuka halaman utama checkout

\section{KESIMPULAN}

Berdasarkan hasil dan pembahasan tersebut maka dapat ditarik kesimpulan sebagai berikut: 
1.) Memperoleh keberhasilan dalam menerapkan teknologi informasi sebagai alat komunikasi dalam transaksi antarbisnis

2.) Memperoleh keberhasilan dalam membangunan sistem informasi sebagai kendali pengoperasian penjualan produk.

3.) Mengetahui keberhasilan kinerja website sebagai media pemasaran secara online.

4.) Perlu dikembangkan lagi mengenai tampilan halaman yang lebih baik agar pengguna nyaman menggunakan sistem

\section{DAFTAR PUSTAKA}

[1] Firli Irhamni, Bain Khusnul Khotimah, Budi Dwi Satoto, "Sistem Informasi ECommerce Produk Unggulan Usaha Mikro dan Menengah (UMKM) Batik." jurnal ilmiah NERO Vol.2 No.3, 2016.

[2] Andri Prasetyo, Rahel Susanti, "Sistem Informasi Penjualan Berbasis Web Pada PT Cahaya Sejahtera Sentosa Blitar." Jurnal Ilmiah Teknologi dan informasi ASIA (JITIKA) Vol.1o No.2, Agustus 2016.

[3] Agus Irawan, Mey Risa, Muhammad Ayyas M, Adam Elya S, "Perancangan Sistem Informasi Penjualan Pakaian pada CV Nonninth Inc Berbasis Online." Jurnal Positif, Vol.3, No.2, 2017.

[4] Mikhael Ferdika, Heri Kuswara, "Sistem Informasi Penjualan Berbasis Web Pada PT Era Makmur Cahaya Damai Bekasi." Information System For Educators and professionals Vol.1, No.2, Juni 2017.

[5] Elvia. (2017). Sistem Informasi Penjualan Kendaraan Online Pada PT Adira Multi Finance Berbasis, Banjarmasin

[6] Jubilee. (2008). Mengenal Pemrograman Database. Jakarta:PT Elex Media Komputindo.

[7] Salim, J. (2008). Buku Pintar Bisnis Online. Jakarta: PT Elex Media Komputindo.

[8] Indrajani. (2010). Database System. Jakarta: PT Elex Media Komputindo.

[9] Setiawan, M. (2011). Jurnal Kompak STIMIK IKMI. Aplikasi Pengendalian Kas
Kecil Untuk Kelancaran Rutinitas Operasional Pada Toko Buku Gramedia Cirebon Di Kota Cirebon, Hal. 19 Vol. 3 No.1, 2018.

[10] Raharjo, B. (2014). Belajar Otodidak Membuat Database Menggunakan Mysql. Bandung:Informatika. 